\title{
The Effect of additive on performance and shelf-stability of HSX-1/PCBM photovoltaic devices
}

\author{
Weiwei Li, Yi Zhou, Viktor Andersson, Mattias Andersson, Yi Thomann, Clemens Veit, \\ Kristofer Tvingstedt, Ruiping Qin, Zhishan Bo, Olle Inganäs, \\ Uli Wuerfel and Fengling Zhang
}

\section{Linköping University Post Print}

N.B.: When citing this work, cite the original article.

Original Publication:

Weiwei Li, Yi Zhou, Viktor Andersson, Mattias Andersson, Yi Thomann, Clemens Veit, Kristofer Tvingstedt, Ruiping Qin, Zhishan Bo, Olle Inganäs, Uli Wuerfel and Fengling Zhang, The Effect of additive on performance and shelf-stability of HSX-1/PCBM photovoltaic devices, 2011, Organic electronics, (12), 9, 1544-1551.

http://dx.doi.org/10.1016/j.orgel.2011.05.028

Copyright: Elsevier Science B.V., Amsterdam. http://www.elsevier.com/

Postprint available at: Linköping University Electronic Press http://urn.kb.se/resolve?urn=urn:nbn:se:liu:diva-69770 


\section{The Effect of Additive on Performance and Shelf-Stability of HSX-1/PCBM Photovoltaic Devices}

Weiwei Li ${ }^{\dagger}$ Yi Zhou, ${ }^{\dagger}$ B. Viktor Andersson, ${ }^{\dagger}$ L. Mattias Andersson, ${ }^{\dagger}$ Yi Thomann, ${ }^{{ }^{*}}$ Clemens Veit, ${ }^{\S}$ Kristofer Tvingstedt, ${ }^{\dagger}$ Ruiping Qin, ${ }^{\ddagger}$ Zhishan Bo, ${ }^{\ddagger}$ Olle Inganäs, ${ }^{\dagger}$ Uli Würfel, ${ }^{\S}$ and Fengling Zhang ${ }^{\dagger *}$

${ }^{\dagger}$ Department of Physics, Chemistry and Biology (IFM), Linköping University, SE-581 83, Sweden ${ }^{\ddagger}$ College of Chemistry, Beijing Normal University, Beijing 100875, China

${ }^{\S}$ Freiburg Materials Research Centre, Stefan-Meier-Str.21, Freiburg 79104, Germany ${ }^{\S}$ Fraunhofer Institute for Solar Energy Systems, Heidenhofstr. 2, 79104 Freiburg, Germany

*Corresponding author. Tel: +46 13281257; Fax: +46 13137568

E-mail address:fenzh@ifm.liu.se (F. L. Zhang)

Submitted to Organic Electronics as a regular paper. 
Abstract How 1,8-diiodooctane (DIO) enhances performance of polymer solar cells based on polymer HXS-1 and fullerene [6,6]-phenyl $\mathrm{C}_{71}$-butyric acid methyl ester $\left(\mathrm{PC}_{71} \mathrm{BM}\right)$ from $3.6 \%$ to $5.4 \%$ is scrutinized with several techniques by comparing devices or blend films spin-coated from dichlorobenzene $(\mathrm{DCB})$ to those from DCB/DIO (97.5:2.5 v/v). Morphology of blend films is examined with atomic force microscopy (AFM), transmission electron microscopy (TEM) and electron tomography (3-D TEM), respectively. Charge generation and recombination is studied with photoluminescence, and charge transport with field effect transistors. The morphology with domain size in 10-20 nm and vertical elongated clusters formed in DIO system is supposed to facilitate charge transport and minimize charge carrier recombination, which are the main reasons for enhancing power conversion efficiency (PCE) from 3.6\% (without DIO) to 5.4\% (with DIO). Furthermore, a two year inspection shows no significant impact of DIO on the shelf-stability of the solar cells. No visible degradation in the second year indicates that the morphology of the active layers in the devices is relatively stable after initial relaxation in the first year.

KEYWORDS. Organic solar cell; additive; morphology; shelf-stability; phase separation.

\section{Introduction}

Bulk heterojunction polymer solar cells (PSCs) with two interpenetrating components as electron donor and acceptor have been intensively investigated for their potential applications [1]. To improve the device performance, new polymers with preferred optoelectronic properties in the form of low band-gap, have been synthesized in order to absorb more solar light [2-4]. Parallel with material development, various fabrication techniques $[1,5,6]$ and device structures have been extensively explored [7-12]. In the past decade, much progress has been made on PSCs in terms of PCE [13-21] with the highest reported value over $8 \%$ [22]. Morphology of active layers in PSCs plays a critical role in determining performance of PSCs because charge carrier generation, recombination and transport are all influenced by spontaneously formed micro/nanostructure of the active layers during solution processing [23-26]. Excitons are dissociated into electrons and holes under strong electric field or/and at 
the interface between materials with different electron affinity, named donor and acceptor. The diffusion length of excitons is only about $10 \mathrm{~nm}$, which limits the distance between donor and acceptor. A fine mixture of donor and acceptor with small domain size and a large interface is therefore expected to be favorable for dissociating polymer Frenkel excitons. The intermolecular bound charge pairs, or charge transfer (CT) states, which are assumed to be formed after the ultrafast splitting of the Frenkel exciton, then needs to be dissociated as well. What determines the dissociation rate of this state, and the generation rate of fully free carriers is currently debated, but it has been suggested that larger domains appears to be beneficial $[27,28]$. Furthermore, bi-continuous paths or continuous donor and acceptor phases are needed for successfully transporting the free electrons and holes to the corresponding electrodes, and prevent them from recombining (bimolecularly). Therefore, the optimum morphology of the active layer is actually a trade-off between charge carrier generation and transport for solution-processed PSCs. However, ideal morphology of the active layers, which strongly depends on the solubility and miscibility of two components, can rarely be spontaneously formed during solution-processing. Therefore some treatments, such as thermal treatments, mixed solvents or adding suitable additives to solvents, are usually employed to tune the morphology of the active layers to optimize performance of PSCs [23, 29-32]. For instances, significant morphology and performance changes could be achieved by mixing two solvents in APFO-3:PCBM system [30]; the PCE of PSCs based on PCPDTBT:PC $\mathrm{P}_{71} \mathrm{BM}$ was doubled by adding high boiling point alkanethiols into chlorobenzene (CB) $[32,33]$. Recently, considerable improvement of PCEs in PSCs by tuning the morphology of active layers with various additives has been demonstrated and becomes a more attractive method due to its simplicity and production compatibility, compared with thermal treatment $[21,34,35]$. DIO is a most commonly used additive, which has been proved enhancing PCE in PSCs based on several different polymers. However, beyond morphology changes, how DIO enhances performance in different polymer fullerene systems has not been fully understood, yet. To the best of our knowledge, there is also no report regarding the impacts of DIO on device stability. 
Following the demonstration of a PCE of 5.4\% in the PSCs based on HXS-1 and PC ${ }_{71}$ BM processed from DCB/DIO in our previous short communication [36], in this paper, the impacts of DIO on performance of PSCs are intensively investigated with the combination of several cutting edge methods. The clear connection between the morphology of the active layer with the charge generation, recombination and transport indicates that DIO improves PCE of PSCs through tuning the morphology of the active layer with specific stoichiometry $(1: 2.5 \mathrm{w} / \mathrm{w})$, to an appropriate domain size and favorable vertical bulk interpenetrating distribution, which leads to a higher photocurrent $\left(J_{\mathrm{sc}}\right)$ and a fill factor (FF). In addition, the stability of PSCs is essential for commercialization. Therefore, the impact of DIO on shelf-stability is also studied in this paper.

\section{Experimental}

The device optimization was carried out in two labs. PSCs with the structure of ITO/PEDOT:PSS/HXS-1:PC ${ }_{71} \mathrm{BM} / \mathrm{LiF} / \mathrm{Al}$ for investigation on DIO effects are mostly fabricated and characterized at Linköping University using the same setup and procedure as described in reference [37]. PSCs for shelf-stability study are fabricated and characterized at Freiburg Materials Research Centre as illustrated in reference [36]. All active layers of PSCs and blend films for PL, morphology study and transport measurement are spin-coated from either DCB or DCB/DIO (97.5:2.5, v/v). Detail descriptions of mobility measurements can be found in reference [38]. PL spectra of all films are recorded with a sensitive CCD Si array detector at wavelengths throughout the visible region and near IR region to $1050 \mathrm{~nm}$ [39].

The topographies of the active layers are imaged with AFM, using a Dimension 3100 system (Digital Instruments/Veeco) operating in tapping mode. Silicon cantilevers (NSG10) with a force constant of 5.5-22.5 N/m, a resonance frequency of 190-325 kHz, and a tip curvature radius of $10 \mathrm{~nm}$ are used. TEM specimens are prepared by detaching a BHJ film from the substrate in deionized water. The film is floating on the water surface, and is picked up with a copper grid. TEM images are obtained with a LEO 912 OMEGA (Zeiss) transmission electron microscopy operated at $30 \mathrm{kV}$ under proper defocus 
conditions. The defocus value of TEM is about $700 \mathrm{~nm}$ for $40000 \mathrm{X}$ magnification, which corresponds to the TEM images with $100 \mathrm{~nm}$ scale bar and $8 \mu \mathrm{m}$ for $8000 \mathrm{X}$ magnification, which corresponds to the TEM images with $1 \mu \mathrm{m}$ scale bar. Films for 3-D TEM are prepared by dissolution of the PEDOT:PSS layer and transfer of the films to a copper grid, as in the TEM-measurements. $10 \mathrm{~nm}$ gold particles are placed on the surface of the films and used for image alignment in the reconstruction process. Tilt series are obtained using a FEI CM200 FEG microscope with a CCD with $24 \mu \mathrm{m}$ pixel size. Images are obtained with one degree increment from $-65^{\circ}$ to $65^{\circ}$ for the film without DIO and from $-68^{\circ}$ to $68^{\circ}$ for the film with DIO. Magnification and postmagnification are 20000 times and 1.531, respectively. Underfocus is set to $2 \mu \mathrm{m}$. Three-dimensional reconstructions are produced with filtered back projection of the images, with software produced at Karolinska Institute (Stockholm, Sweden), and visualized with bob [40].

\section{Results and Discussion}

\subsection{The effect of additive on photovoltaic device performance}

The external quantum efficiency (EQEs) of the two kinds of PSCs (without or with DIO) under monochromatic light illumination and $I-V$ characteristics under AM1.5 $\left(100 \mathrm{~mW} / \mathrm{cm}^{2}\right)$ are recorded and shown in Fig. 1(a) and 1(b), respectively. EQE of the DCB cell is similar in shape to that of the DCB/DIO cell, but somewhat lower, which maybe caused by charge recombination and/or transport indicated by field dependence of I-V curve shown in Fig. 1(b). For comparison, the device performance parameters $\left(J_{\mathrm{sc}}, V_{\mathrm{oc}}, \mathrm{FF}\right.$ and PCE) of the two kinds of PSCs are summarized in Table 1. With DIO, $J_{\mathrm{sc}}$ is

increased from $8.3 \mathrm{~mA} / \mathrm{cm}^{2}$ to $9.8 \mathrm{~mA} / \mathrm{cm}^{2}$ and $\mathrm{FF}$ from 0.51 to 0.69 , which lead to an enhancement of PCE from $3.6 \%$ to $5.4 \%$ (a higher PCE of $5.9 \%$ can be reached in diodes with a smaller active area of about $4 \mathrm{~mm}^{2}$ ), though there is a small reduction of $V_{\mathrm{oc}}$ from $0.85 \mathrm{~V}$ to $0.81 \mathrm{~V}$. It is well known that $J_{\mathrm{sc}}$ of PSCs is sensitive to many factors, but FF is mainly determined by transport property of active layers and their contact with electrodes. A $V_{\text {oc }}$ drop, in this case by $40 \mathrm{mV}$, suggests that ordering $[32,41,42]$ of the active layer is induced by DIO, which is usually favorable for charge transport. Therefore, enlarged 
$J_{\text {sc }}$ and FF combine with decreased $V_{\text {oc }}$ imply that the following discussed morphology of the active layer in $\mathrm{DCB} / \mathrm{DIO}$ cells enables more efficient charge carrier transport to the electrodes than DCB cells.

\subsection{The effect of additive on the morphology of the active layers}

Three kinds of microscopes are employed to examine the morphology variation between films cast from DCB and DCB/DIO. First, the topographies of pure HXS-1 films spin-coated from DCB and DCB/DIO are imaged with AFM where significantly different height images are observed (see Fig. 2(a) and 2(b)). The HXS-1 film from DCB/DIO exhibits much rougher surface with larger aggregations than in the film from DCB, This indicates that DIO can induce the formation of compact chain packing of HXS-1 and crystallization in aggregation form. The corresponding phase image of the HXS-1 film from DCB/DIO shown in Fig. 2(d) reveals fine fibril features contrasting with the featureless phase image of the HXS-1 film from DCB (Fig. 2(c)). This is in accordance with the finding in our previous communication [36]. HXS-1 is a planar polymer designed for facilitating polymer chain packing in solid film, which is realized by adding DIO into DCB [36]. The topographies of blends (HXS-1/PC $\left.{ }_{71} \mathrm{BM}\right)$ spin-coated from DCB and DCB/DIO are also imaged with AFM. The roughness of the blends cast from DCB/DIO increases also obviously in compare to that of the blends from DCB as shown in Fig. 2(e) and Fig. 2(f). As seen in the phase image, pronounced nanophase separation in the blend from DCB/DIO (Fig. 2(h)) and barely detectable phase separation of two components in the film from DCB (Fig. 2(g)) are consistent with the morphology of the pure HXS-1 due to its semi-crystalline property. This nanophase separation of HXS-1 and $\mathrm{PC}_{71} \mathrm{BM}$ may be a result of enhanced HXS-1 crystallization, which is again induced by DIO. The size of this feature is measured to be $10-25 \mathrm{~nm}$.

To see the difference of bulk structures of two blends, the morphologies of blend films cast from two solutions are evaluated with TEM. To show both overall view and detailed information of the films, TEM images are recorded at two different scales, $1 \mu \mathrm{m}($ Fig. 3(a) and 3(c)) and $100 \mathrm{~nm}(\mathbf{F i g}$. 3(b) and (d)). Some large features bigger than $150 \mathrm{~nm}$ are observable. TEM images show contrast based on electron density in the thin film, so that the dark areas are assigned to the $\mathrm{PC}_{71} \mathrm{BM}$-rich phase. This 
image contrast is not caused by thickness difference because we know from AFM height image (Fig. 2e) that the film is very even and with a surface roughness being only $0.43 \mathrm{~nm}$. Noticeably, the large phase separation possesses very broad and diffused interface between mixed $\mathrm{PC}_{71} \mathrm{BM}$-rich and HXS-1-rich phases as seen in Fig. 3(a) and 3(b). Such large features with indistinguishable phase interface can only be caused by inhomogeneous mixing of $\mathrm{PC}_{71} \mathrm{BM}$ and $\mathrm{HXS}-1$ from the DCB only solution and they would not influence PSC performance. On the other hand, more homogeneously mixed blend with very fine structure from DCB/DIO can be distinguished in the overview image (Fig. 3c) and the zoomed image (Fig. 3d). This fine structure can also be seen in the film without $\mathrm{PC}_{71} \mathrm{BM}$ (TEM not shown), which means that the fine structure is induced by HXS-1 crystallization. This is in accordance with the AFM results. According the AFM phase images and TEM images, the thickness of the HXS-1 crystalline lamellae could be determined to be about $10-20 \mathrm{~nm}$. Thereafter, $\mathrm{PC}_{71} \mathrm{BM}$ must be excluded from the HXS-1 crystal and reside between the lamellae, forcing a phase separation with the same size as the crystalline structure. To be clearly stated, the phase separation between $\mathrm{PC}_{71} \mathrm{BM}$ and HXS-1 is attributed to the unique crystallization of HXS-1 provoked by DIO. Another thing to be noticed, the film thickness investigated with TEM are about 150-200 nm, which means that features of 10-20 $\mathrm{nm}$ size seen here are stacks through the whole film. Therefore it is somewhat difficult to clearly separate the individual lamellae. Fortunately this problem can be solved with 3-D TEM investigation shown below.

As the performance of PSCs depends on the vertical distribution of the two components in the active layers and free charges are transported in this direction to the collecting electrodes, it is very interesting to use a 3-D TEM to investigate the vertical distribution of HXS-1 and PC ${ }_{71} \mathrm{BM}$. Electron tomography reconstructions [43] are done on blend films cast from DCB and DCB/DIO (Fig. 4(a) and (b)), which show cross section overviews of the two films (ca. $310 \mathrm{~nm}$ wide and $60 \mathrm{~nm}$ deep). These reconstructions are low pass filtered at $10 \mathrm{~nm}$ [43]. In Fig. 4(c) and 4(d) the middle sections (ca $8 \mathrm{~nm}$ thick) in between anode and cathode interfaces of the same reconstructions are displayed, where a low pass filtering at 5 
$\mathrm{nm}$ has been used. Light regions correspond to well scattering domains and dark regions to less scattering domains. The $\mathrm{PC}_{71} \mathrm{BM}$ is the more scattering material of the two [43]. Thus, the light volumes are attributed to the $\mathrm{PC}_{71} \mathrm{BM}$ rich domains while the dark volumes are the polymer rich domains. A coarser film structure in the film spin-coated from DCB/DIO is also found in these images shown in Fig. 4(b) and 4(d). The film without DIO exhibits smaller domains, which are evenly spread throughout the active layer (see Fig. 4(a) and 4(c)), while in the film with DIO the domains are larger and more clustered together (see Fig. 4(b) and 4(d)). Moreover, Fig. 4b shows more vertical continuous elongated clusters formed than that in Fig. 4a, which will facilitate charge carrier transport to collection electrodes.

\subsection{The effect of additive on charge generation}

Both charge generation and recombination depend strongly on the morphology of active layers. It is interesting to see how DIO influence these physical properties by comparing PL spectra under these two specific morphologies. Deteriorating charge generation is expected in DCB/DIO cells because the interface between HXS-1 and $\mathrm{PC}_{71} \mathrm{BM}$ is decreased due to increased domain size induced by DIO as shown in Fig. 2, 3 and 4. To confirm that, the PL spectra of HXS-1:PC ${ }_{71} B M$ films spin-coated from DCB and DCB/DIO excited by a monochromatic light with a wavelength of $405 \mathrm{~nm}$ is recorded (Fig. 5). Pure HXS-1 films show emission in the range of $600-900 \mathrm{~nm}$, with a peak located at $685 \mathrm{~nm}$ (Fig. S2(B) in reference 36). The $\mathrm{PC}_{71} \mathrm{BM}$ film displays a relatively broad emission with a peak at $720 \mathrm{~nm}$ and also a shoulder at $800 \mathrm{~nm}$. As expected, two morphologies result in two different PL spectra. As shown in Fig. 5, very weak emission in the region of $700 \mathrm{~nm}$ originated from pure $\mathbf{H X S}-\mathbf{1}$ and $\mathrm{PC}_{71} \mathrm{BM}$ is observed in the blend film of HXS-1:PC ${ }_{71} \mathrm{BM}$ from DCB indicating efficient charge transfer [36]. However, as a consequence of increasing domain size and lowering the amount of donor-acceptor interfaces by the addition of DIO, the emission peak at $710 \mathrm{~nm}$ dominates the PL of DCB/DIO films, which can most probably be explained by the combined emission from HXS-1 and $\mathrm{PC}_{71} \mathrm{BM}$ due to inefficient charge transfer since too big pure HXS-1 and $\mathrm{PC}_{71} \mathrm{BM}$ domains exist. So from a charge 
transfer point of view, DIO does not introduce a positive impact.

\subsection{The effect of additive on charge carrier recombination}

As shown in Fig. 5, a new broad emission with a peak located at $930 \mathrm{~nm}$ emerges in blend films from DCB, which is attributed to the recombination of interfacial charge transfer states (CTS) [39, 44-49]. There appears to be less CTS emission from DCB/DIO films (Fig. 5), where it can only be seen as in the tail to the pure material emission. The reduced emission from the CTS in blend films from DCB/DIO compared to the blend film from DCB is interesting. Radiative recombination of CTS is a competitor to photocurrent generation in photovoltaic devices, so lower CTS emission is consistent with increased $J_{\mathrm{sc}}$ in DCB/DIO solar cells. Therefore, from a CTS recombination point of view, DIO introduces a positive impact, that is, decrease radiative recombination of CTS in DCB/DIO film, likely due to increasing phase separation in the active layer. Similar results have also been reported recently [47-49].

\subsection{The effect of additive on transport property}

The electrical properties of solar cells are very sensitive to the morphology of the active layers. To verify the different transport situations in the two kinds of PSCs, the $R_{\mathrm{s}}$ and the $R_{\mathrm{sh}}$ are evaluated and listed in Table 1. Upon adding DIO, the $R_{\mathrm{s}}$ of the PSC decreases significantly from $19 \Omega \mathrm{cm}^{2}$ to $6 \Omega \mathrm{cm}^{2}$, which indicates that the geometry induced by DIO facilitates charge carrier transport in the active layer. Meanwhile, four-fold enhanced $R_{\mathrm{sh}}$ of the DCB/DIO cell implies smaller leak current or less recombination than that in DCB solar cells.

Hole and electron mobilities of the films from the two solutions are measured with FET and listed in

Table 2. The hole mobility $\left(\mu_{\mathrm{h}}\right)$ and electron mobility $\left(\mu_{\mathrm{e}}\right)$ of DCB films are $3 \times 10^{-5} \mathrm{~cm}^{2} \mathrm{Vs}^{-1}$ and 1 $\times 10^{-3} \mathrm{~cm}^{2} \mathrm{Vs}^{-1}$, respectively. There appear to be a change in mobilities in the DCB/DIO film, where $\mu_{\mathrm{h}}$ increases to $1 \times 10^{-4} \mathrm{~cm}^{2} \mathrm{Vs}^{-1}$ and $\mu_{\mathrm{e}}$ decreases to $6 \times 10^{-4} \mathrm{~cm}^{2} \mathrm{Vs}^{-4}$, but this might be a measurement related effect. FET measurements might not be entirely appropriate for this material vis-à-vis solar cell performance due to the presence of ordering and spinodal decomposition [50], which may influence the correlation between FET and solar cell structures in terms of mobility. In particular, there might be an 
increase in PCBM concentration at the dielectric interface of the transistor in the DCB film compared to the DCB/DIO film as can be seen in Fig. 4(a) and 4(b), which may be responsible for the measured changes in mobility. Although an increase of the lower mobility agrees well with the increase in FF observed with additive [21], the rather small hole mobility increase and the fact that neither hole or electron mobility is particularly impressive, indicate that some other mechanism, e.g. enhanced charge separation or decreased recombination, is the main reason for the increased FF. This would also be consistent with the larger domains and the possible decrease in CTS emission seen in the films with DIO. From free charge generation and extraction perspective, a favorable morphology is thus probably more important than a high mobility in order to achieve a high FF.

\subsection{The effect of DIO on the shelf-stability of the solar cells}

To study the effect of additive on the shelf-stability of the solar cells, two substrates with 6 solar cells on each cast from DCB and DCB/DIO were fabricated in Freiburg Materials Research Centre. These cells are kept in a glove box filled with $\mathrm{N}_{2}$ and their $I-V$ curves are recorded for two years with different intervals in days, weeks and months after one day initial degradation. After two years, the average $J_{\mathrm{sc}}$, $V_{\text {oc }}, \mathrm{FF}$ and PCE of 6 solar cells on the same substrate $v s$ time are presented in the inset of Fig. 6 together with normalized corresponding performance parameters (Fig. 6). These 12 solar cells behave similar, $V_{\mathrm{oc}}$ increase, FF slightly decrease and $J_{\mathrm{sc}}$ clearly decrease, which result in an overall PCE decrease with time no matter if it is with or without DIO. The PCE and $J_{\text {sc }}$ decrease by $10 \%$ for solar cells cast from DCB and $12 \%$ for those from DCB/DIO, respectively. The slightly difference ( $2 \%)$ in $J_{\text {sc }}$ and PCE degradation between two groups of solar cells is in experimental error. These results indicate that DIO does not produce observable impact on the shelf-stability of solar cells. The major causes for performance degradation of these solar cells can be bleaching or/and morphology changes due to samples kept in the glove box filled with $\mathrm{N}_{2}$. Bleaching in this case may not play a big role because the samples are only exposed to white light during I-V measurement. Therefore, the fact that degradation is

only observable in the $1^{\text {st }}$ year and no obvious degradation in the $2^{\text {nd }}$ year indicates negligible 
morphology variation after one year initial relaxation.

\section{Conclusions}

In conclusion, the performance enhancement in the solar cells based on HXS-1:PC $\mathrm{Fi}_{71} \mathrm{BM}$ by additive DIO is investigated with AFM, TEM, 3-D TEM, PL and FET. The observations from all these different techniques are well consistent with each other and make a clear connection between solar cell performance and morphology. The enhancement of $J_{\mathrm{sc}}$ from $8.3 \mathrm{~mA} / \mathrm{cm}^{2}$ to $9.8 \mathrm{~mA} / \mathrm{cm}^{2}$ and $\mathrm{FF}$ from 0.51 to 0.69 by introducing DIO into DCB is attributed to the pronounced morphology changes of the active layer induced by DIO. All of AFM, TEM and 3-D TEM images show big domains with sizes of 10-20 nm formed in the films of DCB/DIO. Specially, 3-D TEM images further demonstrate vertical continuous elongated clusters formed in DCB/DIO films. Lower PL intensity of CTS emission in the films from DCB/DIO than that from DCB, suggests that once excitons are dissociated at the interface between HXS-1 and $\mathrm{PC}_{71} \mathrm{BM}$ in the active layers, large domains (detected with AFM, TEM and 3-D TEM) are better at separating the holes and electrons in the two phases. All these results propose that beneficial morphology with domain size in 10-20 nm for inefficient charge recombination and vertical elongated clusters for assisting charge transport to the collecting electrodes in DCB/DIO films are the main reasons for the enhanced $J_{\mathrm{sc}}$ of $9.8 \mathrm{~mA} / \mathrm{cm}^{2}$, FF of 0.69 and PCE of $5.4 \%$. The result of two year shelf-stability measurement indicates that DIO has no pronounced impact on the shelf-stability of the PSCs and the morphology is stable after one year initial relaxation.

\section{Acknowledgement}

Financial support by the NSF of China (20834006 and 50821062), and 863 Program (2008AA05Z425), Swedish Energy Agency, Swedish Research Council (VR) and VINNOVA are gratefully acknowledged. The collaboration between LiU and Fraunhofer ISE is also financed by Swedish Energy Agency. Funding of C. Veit and U. Würfel by the German Federal Ministry of Education and Research under the contract number 03SF0331 is gratefully acknowledged. We thank Dr. Sergej Masich at Karolinska Institute for assistance with electron tomography. 


\section{References}

[1] F. C. Krebs, Solar Energy Materials and Solar Cells 93 (2009) 394.

[2] O. Inganäs, F. L. Zhang, M. R. Andersson, Accounts of Chemical Research 42 (2009) 1731.

[3] Y. F. Li, Y. P. Zou, Advanced Materials 20 (2008) 2952.

[4] E. Bundgaard, F. C. Krebs, Solar Energy Materials and Solar Cells 91 (2007) 954.

[5] Y. H. Zhou, F. H. Li, S. Barrau, W. J. Tian, O. Inganas, F. L. Zhang, Solar Energy Materials and Solar Cells 93 (2009) 497.

[6] F. C. Krebs, Solar Energy Materials and Solar Cells 93 (2009) 1636.

[7] Y. H. Zhou, F. L. Zhang, K. Tvingstedt, W. J. Tian, O. Inganäs, Applied Physics Letters 93 (2008) 033302.

[8] G. Dennler, M. C. Scharber, C. J. Brabec, Advanced Materials 21 (2009) 1323.

[9] A. M. Ballantyne, L. Chen, J. Dane, T. Hammant, F. M. Braun, M. Heeney, W. Duffy, I. McCulloch, D. D. C. Bradley, J. Nelson, Advanced Functional Materials 18 (2008) 2373.

[10] J. Gilot, M. M. Wienk, R. A. J. Janssen, Advanced Materials 22 (2010) E67.

[11] S. Sista, Z. R. Hong, M. H. Park, Z. Xu, Y. Yang, Advanced Materials 22 (2010) E77.

[12] F. L. Zhang, M. Johansson, M. R. Andersson, J. C. Hummelen, O. Inganas, Advanced Materials 14 (2002) 662.

[13] F. Huang, K. S. Chen, H. L. Yip, S. K. Hau, O. Acton, Y. Zhang, J. D. Luo, A. K. Y. Jen, J. Am. Chem. Soc. 131 (2009) 13886.

[14] Y. P. Zou, A. Najari, P. Berrouard, S. Beaupre, B. R. Aich, Y. Tao, M. Leclerc, J. Am. Chem. Soc. 132 (2010) 5330.

[15] E. G. Wang, L. Wang, L. F. Lan, C. Luo, W. L. Zhuang, J. B. Peng, Y. Cao, Applied Physics Letters 92 (2008) 033307.

[16] H. Y. Chen, J. H. Hou, S. Q. Zhang, Y. Y. Liang, G. W. Yang, Y. Yang, L. P. Yu, Y. Wu, G. Li, Nature Photonics 3 (2009) 649.

[17] J. H. Hou, H. Y. Chen, S. Q. Zhang, R. I. Chen, Y. Yang, Y. Wu, G. Li, Journal of the American Chemical Society 131 (2009) 15586.

[18] S. H. Park, A. Roy, S. Beaupré, S. Cho, N. Coates, J. S. Moon, D. Moses, M. Leclerc, K. Lee, A. J. Heeger, Nature Photonics 3 (2009) 297.

[19] D. Kitazawa, N. Watanabe, S. Yamamoto, J. Tsukamoto, Appl. Phys. Lett. 95 (2009) 053701.

[20] S. H. Chan, Y. S. Hsiao, L. I. Hung, G. W. Hwang, H. L. Chen, C. Ting, C. P. Chen, Macromolecules 43 (2010) 3399.

[21] Y. Y. Liang, Z. Xu, J. B. Xia, S. T. Tsai, Y. Wu, G. Li, C. Ray, L. P. Yu, Adv. Mater. 22 (2010) E135.

[22] M. A. Green, K. Emery, Y. Hishikawa, W. Warta, Progress in Photovoltaics 19 (2011) 84.

[23] W. L. Ma, C. Y. Yang, X. Gong, K. Lee, A. J. Heeger, Advanced Functional Materials 15 (2005) 1617.

[24] G. Li, V. Shrotriya, J. S. Huang, Y. Yao, T. Moriarty, K. Emery, Y. Yang, Nature Materials 4 (2005) 864.

[25] S. S. van Bavel, M. Barenklau, G. de With, H. Hoppe, J. Loos, Adv. Funct. Mater. 20 (2010) 1458.

[26] V. D. Mihailetchi, H. X. Xie, B. de Boer, L. J. A. Koster, P. W. M. Blom, Advanced Functional Materials 16 (2006) 699.

[27] T. M. Clarke, J. R. Durrant, Chemical Reviews 110 (2010) 6736.

[28] D. J. D. Moet, M. Lenes, M. Morana, H. Azimi, C. J. Brabec, P. W. M. Blom, Applied Physics Letters 96 (2010).

[29] R. B. Aich, Y. P. Zou, M. Leclerc, Y. Tao, Organic Electronics 11 (2010) 1053.

[30] F. L. Zhang, K. G. Jespersen, C. Bjorstrom, M. Svensson, M. R. Andersson, V. Sundstrom, K. Magnusson, E. Moons, A. Yartsev, O. Inganäs, Advanced Functional Materials 16 (2006) 667.

[31] H. W. Tang, G. H. Lu, L. G. Li, J. Li, Y. Z. Wang, X. N. Yang, J. Mater. Chem. 20 (2010) 683. 
[32] J. Peet, J. Y. Kim, N. E. Coates, W. L. Ma, D. Moses, A. J. Heeger, G. C. Bazan, Nature Materials 6 (2007) 497.

[33] J. Peet, C. Soci, R. C. Coffin, T. Q. Nguyen, A. Mikhailovsky, D. Moses, G. C. Bazan, Appl. Phys. Lett. 89 (2006) 252105.

[34] J. S. Moon, C. J. Takacs, S. Cho, R. C. Coffin, H. Kim, G. C. Bazan, A. J. Heeger, Nano Letters $10(2010) 4005$.

[35] C. V. Hoven, X. D. Dang, R. C. Coffin, J. Peet, T. Q. Nguyen, G. C. Bazan, Advanced Materials $22(2010)$ E63.

[36] R. P. Qin, W. W. Li, C. H. Li, C. Du, C. Veit, H. F. Schleiermacher, M. Andersson, Z. S. Bo, Z. P. Liu, O. Inganäs, U. Wuerfel, F. L. Zhang, Journal of the American Chemical Society 131 (2009) 14612.

[37] W. W. Li, C. Du, F. H. Li, Y. Zhou, M. Fahlman, Z. S. Bo, F. L. Zhang, Chemistry of Materials 21 (2009) 5327.

[38] L. J. Lindgren, F. L. Zhang, M. Andersson, S. Barrau, S. Hellstrom, W. Mammo, E. Perzon, O. Inganas, M. R. Andersson, Chemistry of Materials 21 (2009) 3491.

[39] Y. Zhou, K. Tvingstedt, F. L. Zhang, C. X. Du, W. X. Ni, M. Andersson, O. Inganäs, Advanced Functional Materials 19 (2009) 3293.

[40] s. t. w. http://www.3tag.com/bobicol.html.

[41] J. K. Lee, W. L. Ma, C. J. Brabec, J. Yuen, J. S. Moon, J. Y. Kim, K. Lee, G. C. Bazan, A. J. Heeger, Journal of the American Chemical Society 130 (2008) 3619.

[42] D. Di Nuzzo, A. Aguirre, M. Shahid, V. S. Gevaerts, S. C. J. Meskers, R. A. J. Janssen, Advanced Materials 22 (2010) 4321.

[43] B. V. Andersson, A. Herland, S. Masich, O. Inganas, Nano Lett. 9 (2009) 853.

[44] K. Vandewal, K. Tvingstedt, A. Gadisa, O. Inganäs, J. V. Manca, Nature Materials 8 (2009) 904.

[45] I. Haeldermans, K. Vandewal, W. D. Oosterbaan, A. Gadisa, J. D'Haen, M. K. Van Bael, J. V. Manca, J. Mullens, Applied Physics Letters 93 (2008).

[46] D. Veldman, O. Ipek, S. C. J. Meskers, J. Sweelssen, M. M. Koetse, S. C. Veenstra, J. M. Kroon, S. S. van Bavel, J. Loos, R. A. J. Janssen, Journal of the American Chemical Society 130 (2008) 7721.

[47] K. Tvingstedt, K. Vandewal, A. Gadisa, F. L. Zhang, J. Manca, O. Inganäs, Journal of the American Chemical Society 131 (2009) 11819.

[48] M. Hallermann, I. Kriegel, E. D. Como, J. M. Berger, E. V. Hauff, J. Feldmann, Advanced Functional Materials 19 (2009) 3662.

[49] K. Tvingstedt, K. Vandewal, F. L. Zhang, O. Inganas, Journal of Physical Chemistry C 114 (2010) 21824.

[50] S. Nilsson, A. Bernasik, A. Budkowski, E. Moons, Macromolecules 40 (2007) 8291. 
Figures and Tables

(a)

(b)
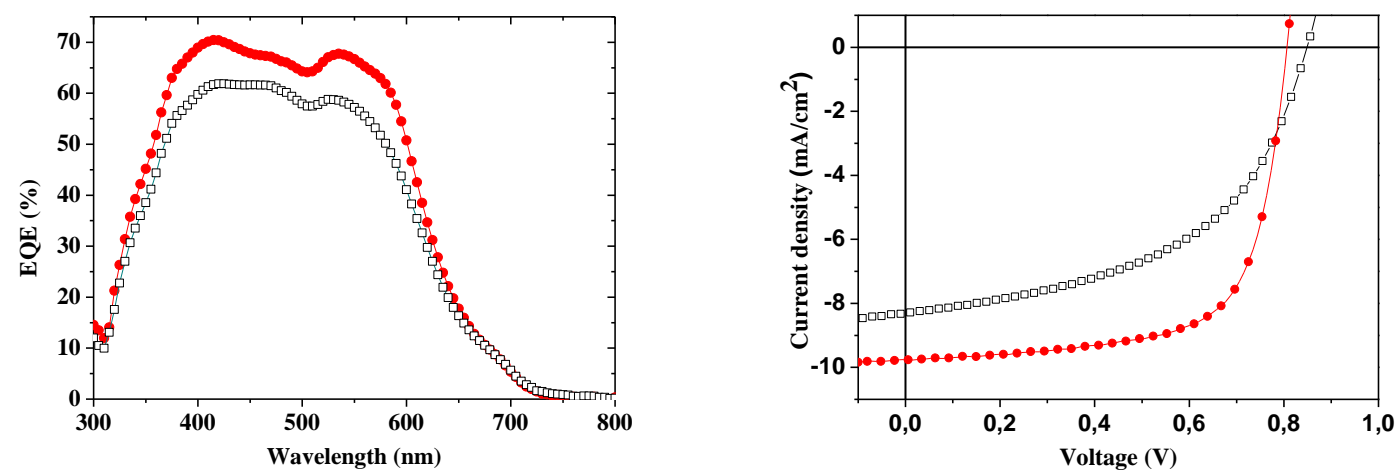

Fig. 1. (a) The EQEs and (b) I-V characteristics of PSCs spin coated from DCB (open squares) and DCB/DIO (filled circles) under AM 1.5 illuminations.
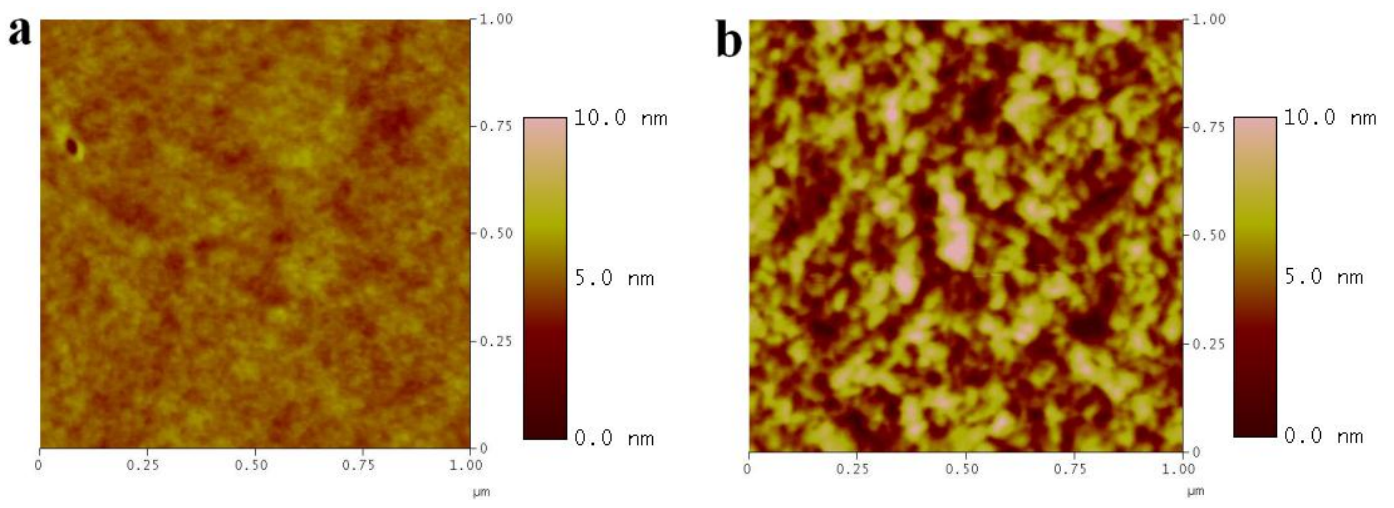

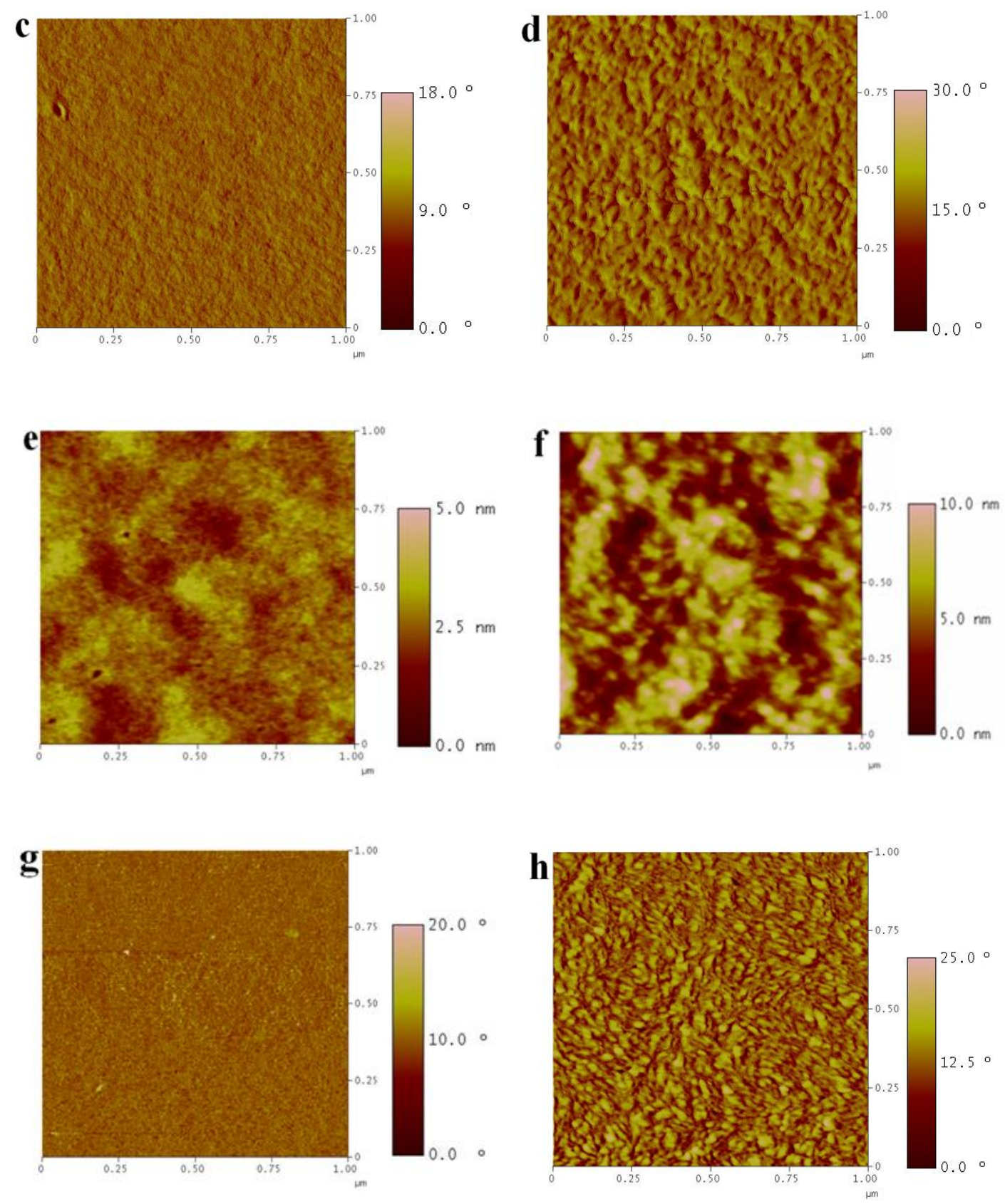

Fig. 2. (a) and (b) are the AFM height images of HXS-1 spin coated from DCB and DCB/DIO $(1 \mu \mathrm{m} \times 1$ $\mu \mathrm{m}$ ), The RMS of (a) and (b) are $0.430 \mathrm{~nm}, 1.859 \mathrm{~nm}$, respectively. (c) and (d) are the phase images corresponding to (a) and (b). (e) and (f) are AFM height images of HXS-1:PC ${ }_{71} \mathrm{BM}$ spin coated from DCB and DCB/DIO. (g) and (h) are the phase images corresponding to (e) and (f). The RMS of (e) and (f) are $0.43 \mathrm{~nm}$ and $1.90 \mathrm{~nm}$, respectively. 
(a)

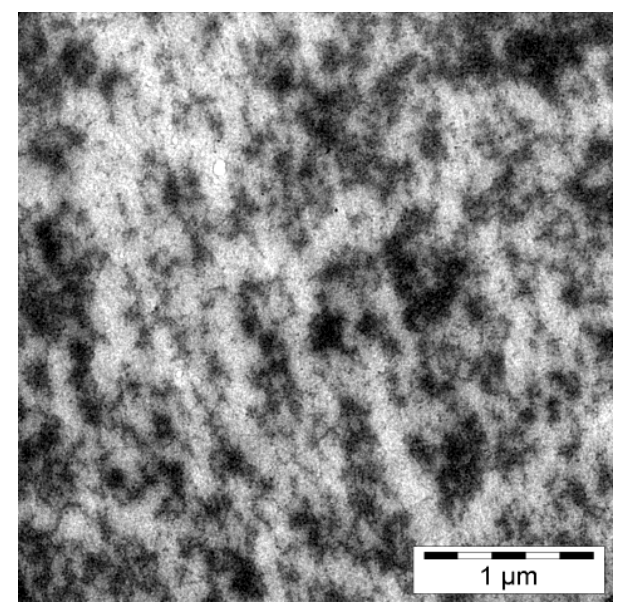

(c)

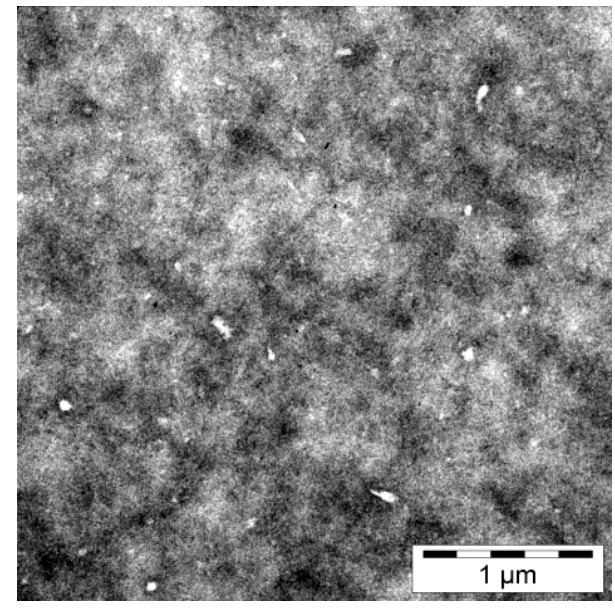

(b)

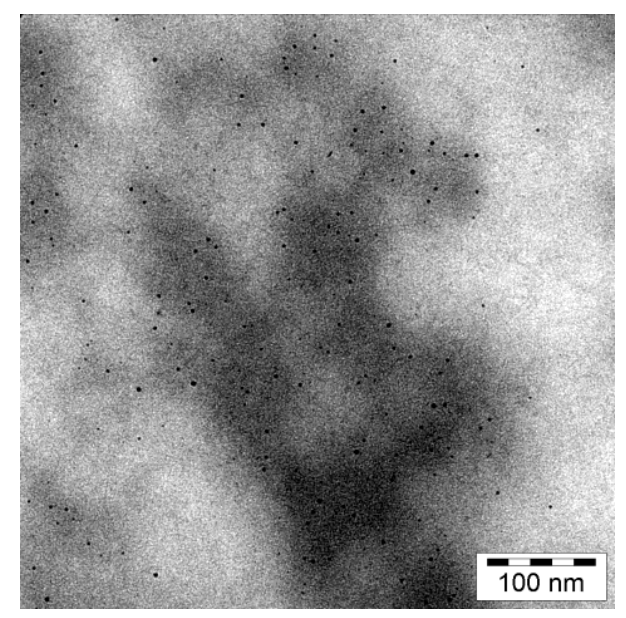

(d)

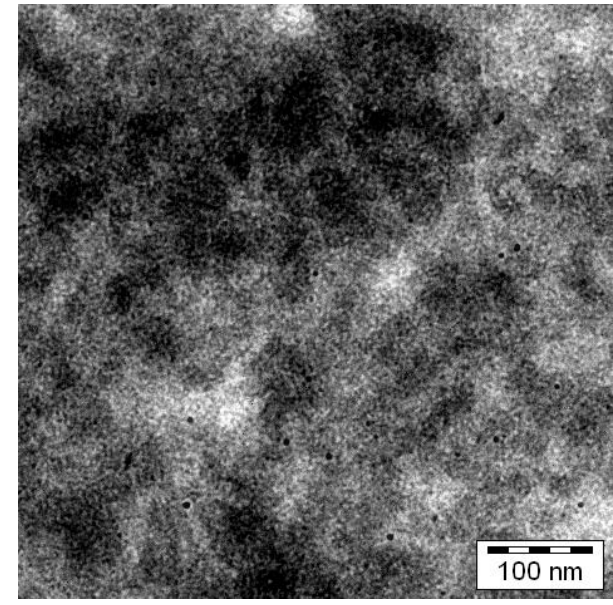

Fig. 3. The TEM images of HXS-1/PC ${ }_{71} B M$ spin-coated from $\mathrm{DCB}$ (a and $b$ ) and DCB/DIO (c and d). 


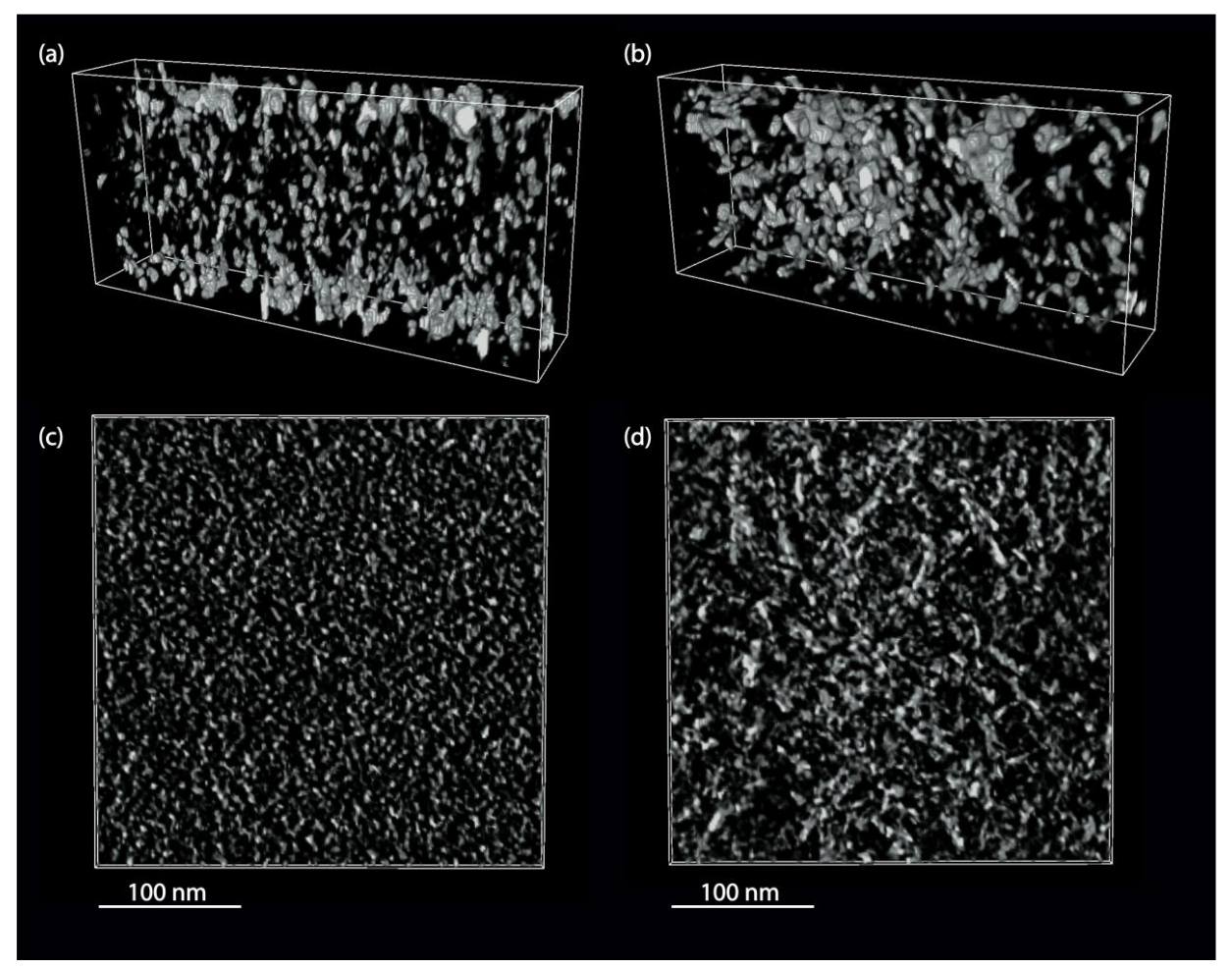

Fig. 4. The cross section overviews of the two blend films cast from DCB (a) and DCB/DIO (b). Image 4(c) and 4(d) are the middle sections (ca $8 \mathrm{~nm}$ thick) of the same reconstructions of 4(a) and 4(b).

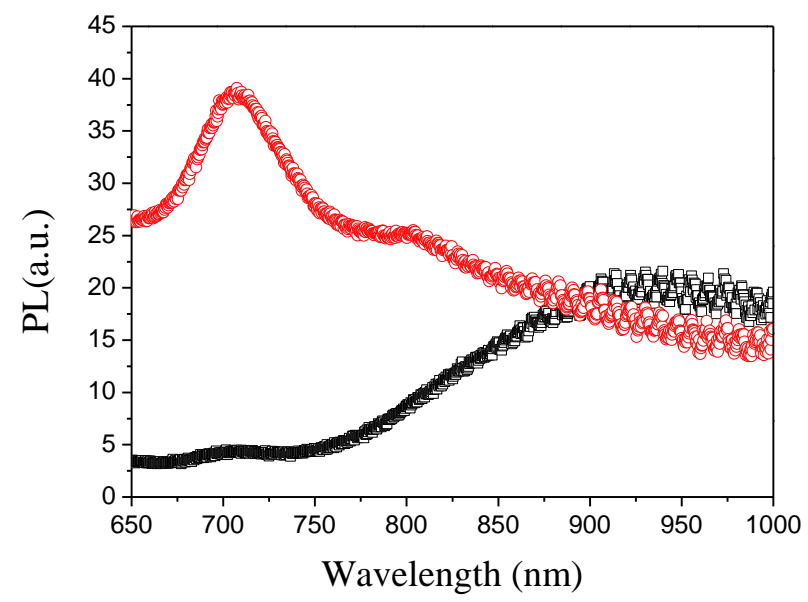

Fig. 5. The PL spectra of HXS-1/PC ${ }_{71} B M$ films spin coated from DCB (black squares) and DCB/DIO (red circles). The excitation wavelength is $405 \mathrm{~nm}$. 

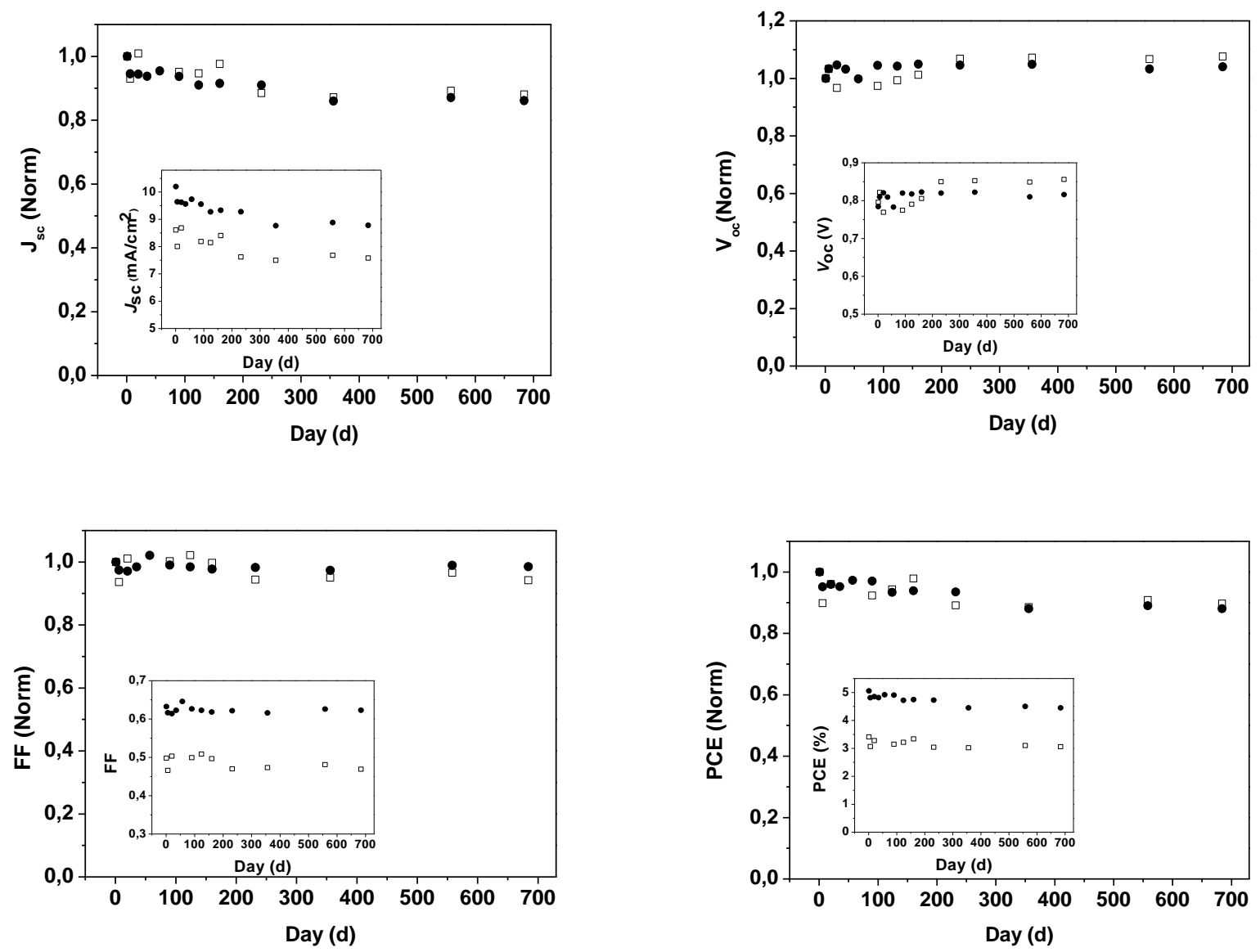

Fig. 6. Normalized and average (inset) performance parameters of HXS-1:PC ${ }_{71} B M$ photovoltaic devices spin-coated from DCB (opened squares) and DCB/DIO (filled circles)

Table 1. Parameters of HXS-1:PC 71 BM solar cells

\begin{tabular}{ccccccc}
\hline Solvent & $J_{\mathrm{sc}}\left[\mathrm{mA} / \mathrm{cm}^{2}\right]$ & $V_{\mathrm{oc}}[\mathrm{V}]$ & $\mathrm{FF}$ & $\mathrm{PCE}$ & $R_{\mathrm{s}}\left[\Omega \mathrm{cm}^{2}\right]$ & $R_{\mathrm{sh}}\left[\Omega \mathrm{cm}^{2}\right]$ \\
\hline DCB & 8.3 & 0.85 & 0.51 & $3.6 \%$ & 19 & 485 \\
& 9.8 & 0.81 & 0.69 & $5.4 \%$ & 7 & 2110
\end{tabular}

Table 2. Hole and electron mobilities of the films from DCB and DCB/DIO

\begin{tabular}{|c|c|c|c|}
\hline Solvent & $\mu_{\mathrm{h}}\left[\mathrm{cm}^{2} \mathrm{Vs}^{-1}\right]$ & $\mu_{\mathrm{e}}\left[\mathrm{cm}^{2} \mathrm{Vs}^{-1}\right]$ & $\mu_{\mathrm{e}} / \mu_{\mathrm{h}}$ \\
\hline $\mathrm{DCB}$ & $3 \times 10^{-5}$ & $1 \times 10^{-3}$ & 33.3 \\
\hline $\mathrm{DCB} / \mathrm{DIO}$ & $1 \times 10^{-4}$ & $6 \times 10^{-4}$ & 6 \\
\hline
\end{tabular}

